\title{
Presentación de Medes (Medicina en español)
}

\author{
Por Tomàs Baiget
}

Baiget, Tomàs. "Presentación de Medes (Medicina en español)". En: El profesional de la información, 2007, noviembre-diciembre, v. 16, n. 6, pp. 664-665.

DOI: $10.3145 /$ epi.2007.nov.15

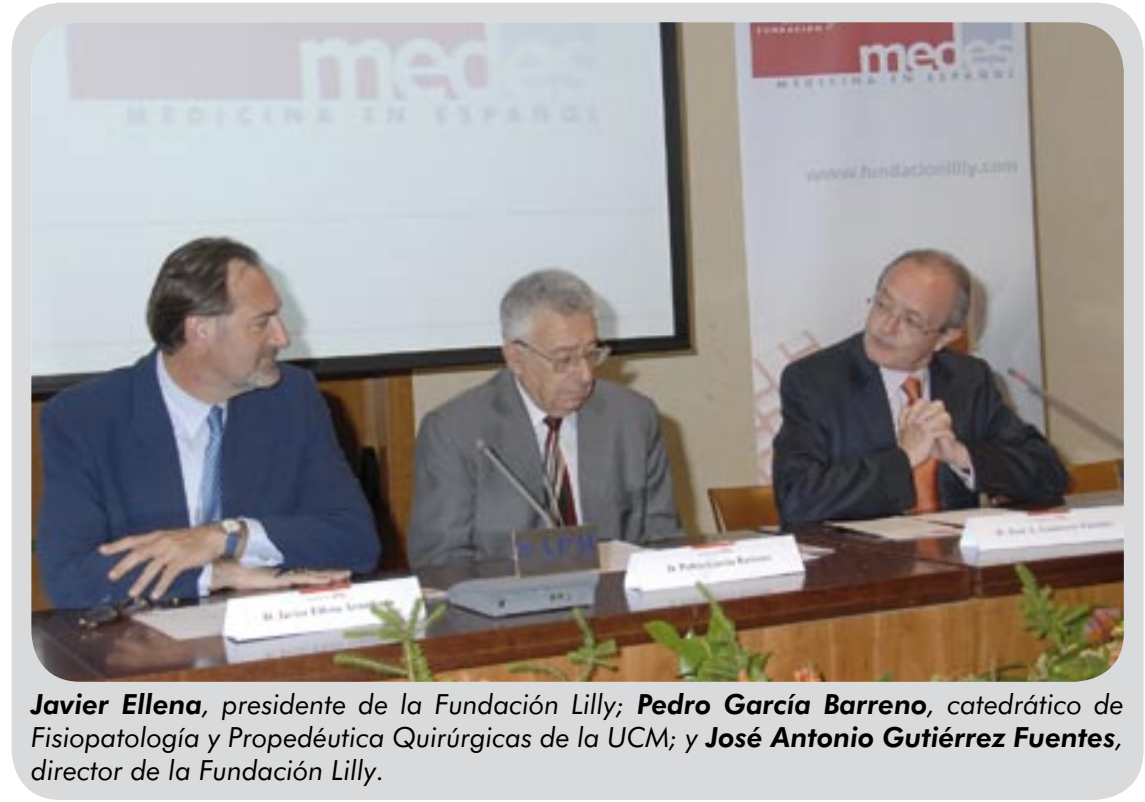

EL 25 DE JUNIO DE 2007 la Fundación Lilly presentó la base de datos Medes, que recoge las referencias bibliográficas con resumen de 55 revistas médicas españolas. En acto presentación participó el catedrático Pedro García Barreno, miembro de la Real Academia Española y de la Real Academia de Ciencias.

En el momento de escribir esta nota Medes contiene 22.000 registros, que pueden consultarse gratuitamente desde el URL:

http://www.fundacionlilly.com/ medes/home.htm

Leemos en la web:

"La iniciativa Medes tiene como objetivo contribuir a promoción de la publicación en revistas biomédicas españolas, así como favorecer su difusión nacional e internacional mediante diversas actividades de formación y divulgación.
Desarrolla la base de datos bibliográfica Medes-Medicina en español, con el propósito de poner a disposición del profesional sanitario, fundamentalmente de la atención primaria, una herramienta de consulta centrada en aspectos de la práctica clínica, mediante una rigurosa selección de contenidos.

En el entorno de la iniciativa Medes se celebra una Jornada anual en la que se debaten temas relacionados con la publicación biomédica en España ${ }^{1}$. Las Jornadas Medes son muy interesantes, pues en ellas participan los mejores especialistas españoles, tanto responsables de política científica y editores de revistas, como evaluadores de artículos, autores, bibliotecarios, documentalistas..., con lo cual se establecen debates muy vivos. En la siguiente dirección pueden verse las transparencias y los vídeos de las ponencias, altamente recomendables: http://www.fundacionlilly.com/ medes/jornadas.htm

Medes cuenta con un Comité Técnico que valida la selección de los contenidos de la base de datos y participa en la elaboración de los programas de las jornadas y un Consejo Asesor compuesto por reconocidos profesionales del mundo de la medicina, la documentación, la publicación y la información científico técnica, con funciones consultivas y de representación".

\section{¿Ciencia en español?}

La respuesta a esta pregunta la encontramos en una publicación de la propia Fundación: "Parece indiscutible que el idioma de la ciencia es hoy el inglés, como lo fueron en otros tiempos el latín, el español o el alemán. Esta hegemonía favorece que los autores prefieran los libros y revistas en inglés para dar a conocer sus trabajos y que se ignoren las investigaciones que se realizan en otros países. No obstante cabría

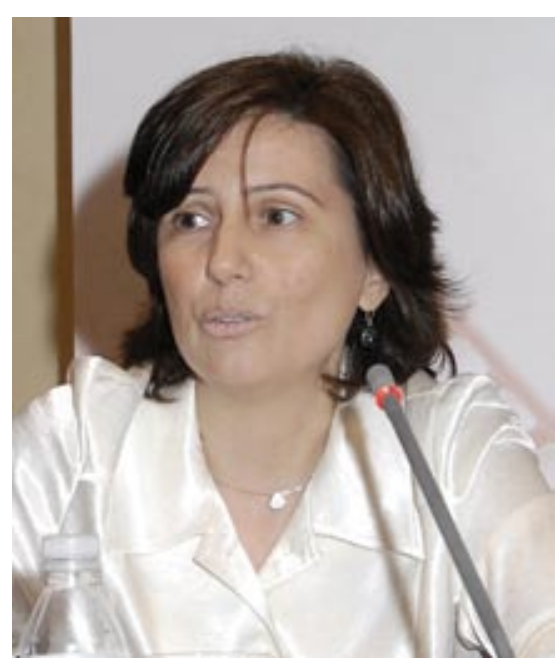

Ángeles Flores, responsable del proyecto Medes 
plantearse que ante trabajos que afectan directamente a la práctica de la medicina en nuestro entorno decisión de publicar sólo en revistas en inglés condena esas investigaciones al olvido: imposibles de entender y por ello carentes de interés para quienes no conocen el idioma".

1. Roldán, Álvaro. $2^{\mathrm{a}}$ jornada de la Fundación Lilly sobre publicación médica en España (Hotel EuroForum, El Escorial, Madrid, 20 nov 2006). En: El profesional de la información, v. 16, n. 1, pp. 78-80.

http://eprints.rclis.org/archive/00009771/

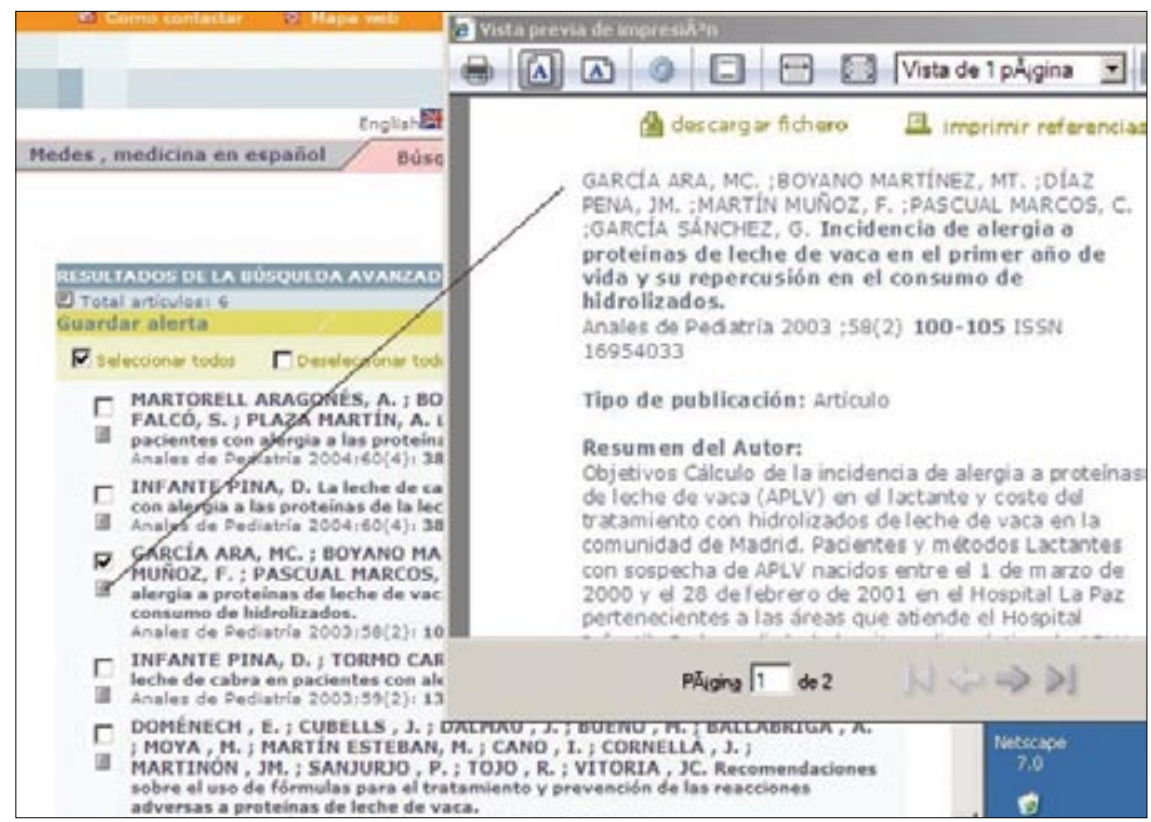

Medes: Visualización de resultados

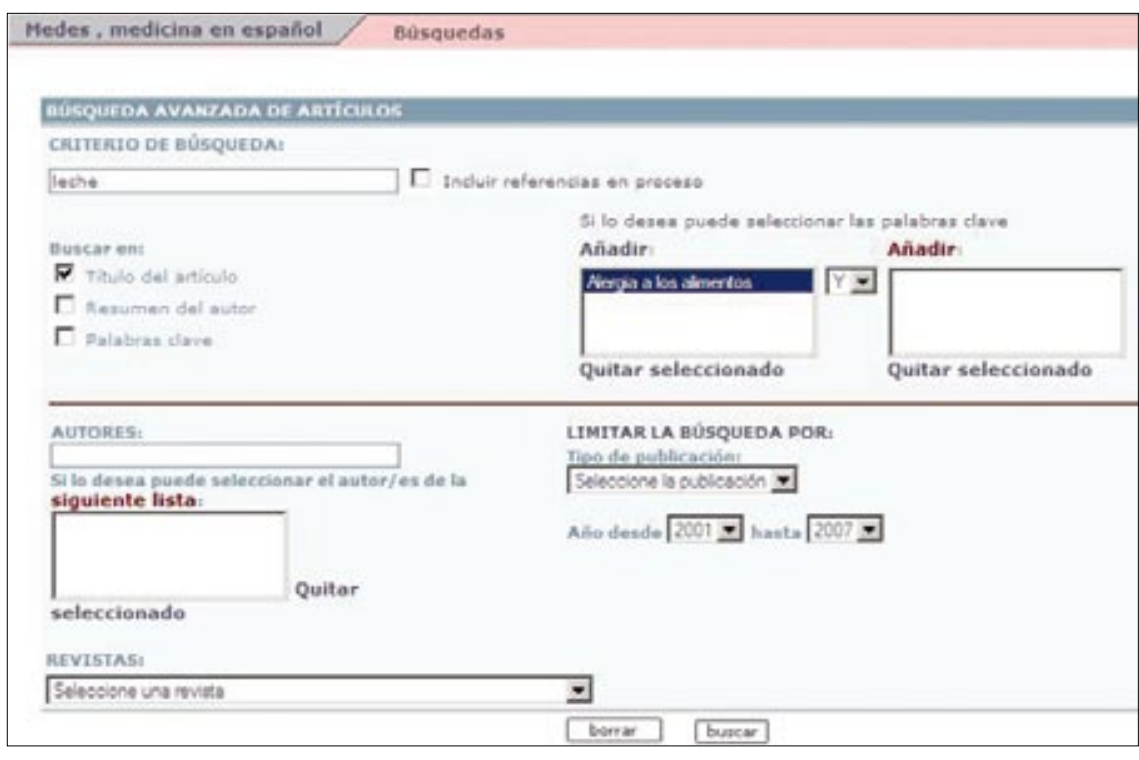

Medes: Búsqueda avanzada
2. Baiget, Tomàs. La publicación médica en España: crónica del curso (El Escorial, Madrid, 12 jul 2005). En: El profesional de la información, v. 14, n. 5, pp. 391-396.

http://eprints.rclis.org/archive/00006192/

Contacto: Ma Ángeles Flores; David García-Cañadillas

Fundación Lilly, María de Molina, $3-1^{\circ} .28006$ Madrid.

Tel.: +34-917 815 070; fax: 917 815079

fundacionlilly@lilly.com http://www.fundacionlilly.com

Tomàs Baiget, baiget@sarenet.es

\section{Próximos temas centrales}

Enero 2008

Marzo 2008

Mayo 2008

Julio 2008

Septiembre 2008

Noviembre 2008
Software libre para bibliotecas Innovación en bibliotecas públicas Presente y futuro de la profesión Libros electrónicos Información en la empresa Redes sociales

Los interesados pueden remitir notas, artículos, propuestas, publicidad, comentarios, etc., sobre estos temas a:

epi@elprofesionaldelainformacion.com 


\section{Spanish Meeting Point}

Stand 732, Conferencia Online Information Londres, 4-6 diciembre 2007

Este año en la Online Information Conference de Londres, la más importante del mundo en materia de contenidos, se podrá visitar el stand Spanish Meeting Point, un punto de encuentro para los profesionales de la información hispanohablantes.

La financiación de este stand ha sido posible gracias a:

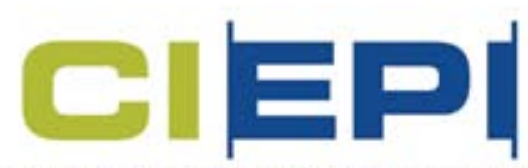

CENTRO INTERNACIONAL PARA LA INVESTIGACIÓN EN ESTRATEGIA Y PROSPECTIVA DE LA INFORMACIÓN
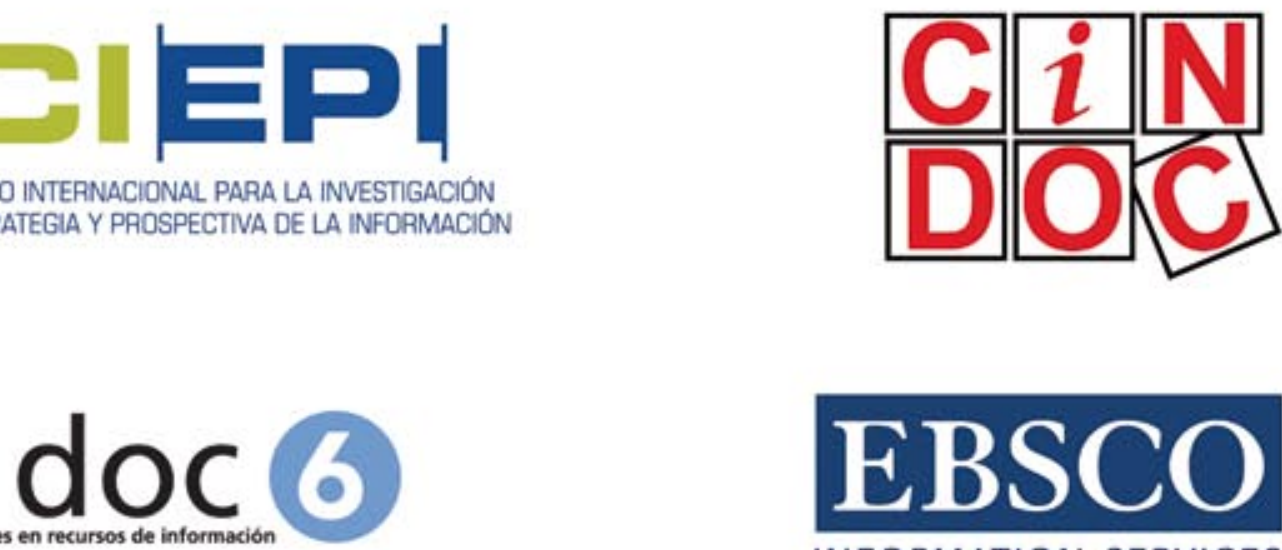

INFORMATION SERVICES

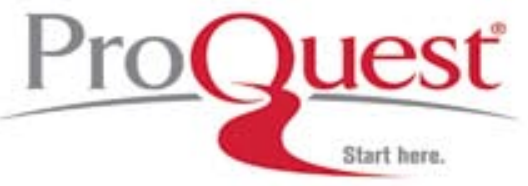

$\underset{\text { Health }}{\text { W.. Wolters Kluwer }}$

Ovid 